\title{
Comparison of two serological methods and a polymerase chain reaction-enzyme immunoassay for the diagnosis of acute respiratory infections with Chlamydia pneumoniae in adults
}

\author{
J. PETITJEAN, F. VINCENT*, M. FRETIGNY, A. VABRET, J. D. POVEDA $\dagger$, J. BRUN* \\ and F. FREYMUTH \\ Laboratory of Human and Molecular Virology, CHRU Caen, Avenue Georges Clemenceau, 14033 Caen Cedex, \\ * Department of Pneumology, CHRU Caen and †Center of Medical Biology, Institut Pasteur Paris, France
}

\begin{abstract}
Chlamydia pneumoniae is a common respiratory tract pathogen. Serological methods currently used for the diagnosis of $C$. pneumoniae infection lack specificity, give ambiguous results from a single serum sample and often provide only a retrospective diagnosis. A prospective study was undertaken to assess whether PCR could be a useful addition to the serological techniques routinely practised for diagnosis. This study investigated 68 adult patients with a diagnosis of acute respiratory infection. Acute and convalescent serological determination of antibodies to $C$. pneumoniae were performed by means of an rELISA test and a micro-immunofluorescence (MIF) test. Nasopharyngeal aspirates or bronchoalveolar lavage specimens and bronchial aspirates obtained from the 68 patients were evaluated by PCR-enzyme immunoassay (PCR-EIA) for the presence of $C$. pneumoniae and by immunofluorescence assay and cell culture for virus identification. Mycoplasma pneumoniae serology was also performed. Eight patients (11.8\%) were positive by either rELISA or PCR-EIA, or both, with an infection rate of $5(18.5 \%)$ of 27 in patients with community-acquired pneumonia, 2 (9\%) of 22 in asthmatic patients and $1(5 \%)$ of 19 in patients with an exacerbation of chronic obstructive pulmonary disease. Serological evidence of acute infection was found in four of these patients with the rELISA test and in three others with the MIF test. PCR-EIA detected $C$. pneumoniae DNA in four specimens, but there were concordant results with both rELISA and PCR-EIA in only one patient. A positive PCR-EIA was also obtained in a patient who did not show an antibody response in acute serum. The discrepancy between serological and PCR-EIA results reflects the difficulties in routine laboratory diagnosis of $C$. pneumoniae infection and the necessity for further studies with optimised techniques.
\end{abstract}

\section{Introduction}

Chlamydia pneumoniae is the third species of the genus Chlamydia and is an important respiratory pathogen [1-5]. It has been implicated as a cause of c. $10 \%$ of cases of community-acquired pneumonia. It has also been associated with bronchitis, pharyngitis, sinusitis and otitis in both children and adults [1-3]. Sero-epidemiological studies have shown that $>50 \%$ of adults world-wide have serological evidence of previous infection. Seroprevalence increases slightly with age, and is higher in men than in women. Most primary

Received 29 July 1997; revised version accepted 1 Dec. 1997.

Corresponding author: Dr J. Petitjean. infections occur in children and young adults, and the majority of infections are subclinical or asymptomatic. Re-infection and reactivation are common in adults, enhanced by immunosuppression [6] and can lead to chronic carriage. Persistent infection with $C$. pneumoniae has been associated with some chronic conditions such as coronary heart disease [7-10], chronic asthma and bronchitis [11], chronic pharyngitis [12] and chronic obstructive pulmonary disease (COPD) [13].

Diagnosis of $C$. pneumoniae infection is usually made serologically with the micro-immunofluorescence (MIF) test [2]. Single-point serology is the most frequent practice, but it is not reliable for an accurate diagnosis of acute infection. Difficulties arise because of the late onset of antibody production, the frequency 
of re-infection or reactivation without an IgM response and the persistence of IgG for many months or years [2]. Ambiguous results or retrospective serological diagnosis are unhelpful for patient management and thus newer techniques are needed. Direct detection of $C$. pneumoniae by cell culture could provide more accurate diagnosis, but it is insensitive and difficult to perform. Recently, the polymerase chain reaction (PCR) has been investigated as a method for the detection of $C$. pneumoniae in clinical specimens. Initial studies have reported highly sensitive and specific results [14-16]. The present study was designed to compare the performance of two serological methods with PCR-EIA in the diagnosis of C. pneumoniae in patients with acute lower respiratory tract infections.

\section{Materials and methods}

\section{Patients}

Sixty-eight adult patients (29 female and 39 male; mean age 68.2 years, range $32-90$ years), who required admission to the Pneumology Units of the University Hospital of Caen for acute lower respiratory tract infection, were enrolled in the study between Jan. and Oct. 1995. They were distributed into three groups according to clinical and radiological criteria as follows: community-acquired pneumonia $(n=27)$, exacerbation of COPD $(\mathrm{n}=19)$ and acute exacerbation of asthma or asthmatic bronchitis $(n=22)$. Community-acquired pneumonia was defined as a typical clinical illness with a pulmonary infiltrate on the chest radiograph. The patients with an exacerbation of COPD were characterised by a worsening cough, in the presence of purulent or mucopurulent sputum, with or without fever and increasing dyspnoea. Finally, the asthmatic group was composed of patients affected by asthmatic bronchitis (acute bronchitis with bronchospasm) or by an acute exacerbation of asthma. The latter was defined as a reported increase in asthma symptoms or in the use of $\beta 2$-agonists, or both, with objective evidence of wheezing and a fall of $>20 \%$ in the forced expiratory volume in $1 \mathrm{~s}$ (FEV1). Increased dyspnoea and the presence of sputum were optional criteria.

All patients were investigated by both serology and PCR to assess the presence of $C$. pneumoniae, by serology for Mycoplasma pneumoniae and by immunofluorescence assay (IFA) and viral isolation techniques for respiratory viruses (Table 1).

\section{Specimen collection}

Posterior nasopharyngeal aspirates (NPAs) were obtained from 59 patients, and placed in $2 \mathrm{ml}$ of sucrosephosphate-glutamate transport medium. Samples were processed immediately for virus isolation $(0.2 \mathrm{ml})$ and IFA $(0.8 \mathrm{ml})$, and $1 \mathrm{ml}$ was stored at $-70^{\circ} \mathrm{C}$ for PCREIA assay. The same procedure was applied to the broncho-alveolar lavage (BAL) specimens and bronchial aspirates (BAs) obtained from the remaining nine patients. BA and BAL were performed under standard conditions if a clinical indication for bronchoscopy was present. BAL specimens were collected from four patients, BA from one patient and both $\mathrm{BA}$ and $\mathrm{BAL}$ specimens from four patients.

A serum specimen was collected at the time of enrolment from 67 patients (acute serum). One or two convalescent serum specimens, collected 10-21 days after the first specimen, were available from only 27 patients $(38 \%)$. Eleven other serum specimens $(17.6 \%)$, collected $<8$ days after the first sample, were excluded from the analysis as the interval between the two samples was too short. All serum samples were stored at $-20^{\circ} \mathrm{C}$.

\section{PCR-EIA assay}

The PCR-EIA was performed with two synthetic oligonucleotide primers (sense 76-103: 5' CAGAAGAAAAAAATAAACATGCGATAGG 3'; antisense 231-258: 5' AACAGGTGCTGGCTTTGTTTCCGCACTA $\left.3^{\prime}\right)$ and a $5^{\prime}$-biotinylated probe $\left(150-175: 5^{\prime}\right.$ CGCTAACGAGTATGGCGAGTTGCTT $3^{\prime}$ ) based on the sequence of the gene encoding the $60-\mathrm{kDa}$

Table 1. Summary of the diagnostic methods used for different respiratory pathogens and main results

\begin{tabular}{|c|c|c|c|c|}
\hline Bacteria and viruses & Specimen & Number tested & Detection method & Positive result $(\%)$ \\
\hline \multirow[t]{2}{*}{ C. pneumoniae } & NPA/BAL/BA & $59 / 8 / 5$ & PCR-EIA & $4^{*}(5.9)$ \\
\hline & Serum & 67 & rELISA/MIF & $4 / 7(5.9 / 10.4)$ \\
\hline M. pneumoniae & Serum & 67 & ELISA & $1(1.5)$ \\
\hline Influenza virus $A$ & NPA/BAL/BA & $59 / 8 / 5$ & IFA/NIT & 0 \\
\hline Influenza virus $\mathrm{B}$ & $\mathrm{NPA} / \mathrm{BAL} / \mathrm{BA}$ & $59 / 8 / 5$ & IFA/NIT & $2^{*}(2.9)$ \\
\hline Parainfluenza virus 1 & $\mathrm{NPA} / \mathrm{BAL} / \mathrm{BA}$ & $59 / 8 / 5$ & IFA/NIT & 0 \\
\hline Parainfluenza virus 2 & $\mathrm{NPA} / \mathrm{BAL} / \mathrm{BA}$ & $59 / 8 / 5$ & IFA/VIT & 0 \\
\hline Parainfluenza virus 3 & $\mathrm{NPA} / \mathrm{BAL} / \mathrm{BA}$ & $59 / 8 / 5$ & IFA/NIT & 0 \\
\hline Respiratory syncytial virus & $\mathrm{NPA} / \mathrm{BAL} / \mathrm{BA}$ & $59 / 8 / 5$ & IFA/VIT & $1^{*}(1.5)$ \\
\hline Coronavirus & $\mathrm{NPA} / \mathrm{BAL} / \mathrm{BA}$ & $59 / 8 / 5$ & IFA & $3^{\dagger}(4.4)$ \\
\hline Adenovirus & $\mathrm{NPA} / \mathrm{BAL} / \mathrm{BA}$ & $59 / 8 / 5$ & IFA/VIT & 0 \\
\hline
\end{tabular}

NPA: nasopharyngeal aspirate; BAL, bronchoalveolar lavage; BA, bronchial aspirate; VIT, virus isolation techniques 
cysteine-rich outer-membrane protein (Omp2) of $C$. pneumoniae strain IOL-207 [17]. This set of primers, selected according to the original methodology based on K-tuple frequency disparity, is highly specific [18].

From each NPA specimen, $250 \mu 1$ were treated with $250 \mu \mathrm{l}$ of proteinase K-Tris EDTA lysis solution containing proteinase K (Sigma) $200 \mu \mathrm{g} / \mathrm{ml}$, Nonidet P-40 (Boehringer Mannheim, Germany) $1 \%$ and Tween 20 (Sigma) 1\%. Samples were incubated at $60^{\circ} \mathrm{C}$ for $2 \mathrm{~h}$, extracted by standard phenol-chloroform extraction and precipitated overnight at $-20^{\circ} \mathrm{C}$ in sodium acetate-ethanol. The pellets were washed in ethanol $70 \%$ and resuspended in $50 \mu \mathrm{l}$ of distilled water. PCR was performed in a total volume of $100 \mu \mathrm{l}$ overlaid with two drops of mineral oil. The final mixture contained $1 \times$ PCR buffer $(10 \mathrm{mM}$ Tris, $\mathrm{pH}$ $8.4 ; 50 \mathrm{mM} \mathrm{KCl} ; 2 \mathrm{mM} \mathrm{MgCl}_{2}$; gelatin $0.01 \%$ ), $1 \mu \mathrm{M}$ of each primer, $200 \mu \mathrm{M}$ of deoxynucleoside triphosphates and 2.5 units of Taq DNA polymerase (Perkin Elmer-Cetus). After a first cycle of denaturation at $94^{\circ} \mathrm{C}$ for $5 \mathrm{~min}$, amplification was performed in a Hybaid thermocycler for 40 cycles with the following conditions for each cycle: denaturation $94^{\circ} \mathrm{C}(1 \mathrm{~min})$, annealing $55^{\circ} \mathrm{C}(1 \mathrm{~min})$ and elongation $72^{\circ} \mathrm{C}(1 \mathrm{~min})$. The final elongation step was prolonged to $10 \mathrm{~min}$. Each run included a positive and a negative control. Specimen preparation, PCR set-up, and analyses of the amplification products were all performed in separate rooms. The 183-bp PCR product was resolved on an ethidium bromide-stained agarose $2 \% \mathrm{w} / \mathrm{v}$ gel under UV illumination. The specificity of the PCR products was verified by hybridisation with a $5^{\prime}$ biotinylated probe and detection with the DNA enzyme immunoassay (GEN-ETI-K DEIA Sorin). This detection system is based on hybridisation of amplified DNA with a biotinylated single-stranded DNA probe which is immobilised on the wall of the microtitration plate wells by a streptavidin-biotin bond. The hybrid of the probe and the denatured DNA sample is detected with an anti-DNA monoclonal antibody (MAb) that reacts with the double-stranded DNA PCR product, but not with the single-stranded DNA probe. The addition of an enzyme tracer (anti-mouse IgG labelled with horseradish peroxidase) detects the DNA-antibody bond. The assay was performed as recommended by the manufacturer. The optimal concentration of the biotinylated probe required for the test was $0.5 \mathrm{ng} / \mu 1$. All positive PCR results were confirmed by repeat testing.

\section{Sensitivity and specificity of PCR-EIA}

To evaluate the sensitivity of the PCR-EIA, PCR was performed on DNA extracted from $100-\mu 1$ serial dilutions of a culture supernate of $C$. pneumoniae. A titre of $10^{4}$ inclusion forming units (ifu) was obtained by culture with HEp2 cells and detection of $C$. pneumoniae inclusions after incubation for $96 \mathrm{~h}$ at $37^{\circ} \mathrm{C}$ by indirect immunofluorescence with an anti- $C$. pneumoniae MAb (BMD, France). The PCR test allowed the detection of $10^{-2}$ ifu/ml after hybridisation. The specificity of this test was determined with a panel of 25 viral and bacterial species (Table 2). PCR of $0.1 \mu \mathrm{g}$ of DNA of each species, performed with the $C$. pneumoniae-specific primers, failed to produce the 183-bp fragment and no hybridisation was seen with the probe.

\section{IFA and virus isolation}

For direct IFA, the cells were separated by centrifugation, washed in phosphate-buffered saline, deposited on microscope slides, fixed in acetone and stained with a panel of specific FITC conjugate MAb reagents for influenza virus $\mathrm{A}$ and $\mathrm{B}$, adenovirus, respiratory syncytial virus and parainfluenza 1, 2, 3 (Imagen, Dako Diagnostics). An indirect IFA with a MAb (Argene) was used for coronavirus detection. Cell culture was performed with MRC-5 human embryonic lung fibroblasts in $25-\mathrm{cm}^{2}$ flasks and with two continuous cell lines (MDCK and $\mathrm{NCl}$ ) in 24-well cell culture plates $\left(\right.$ Costar $\left.^{\circledR}\right)$. MRC-5 cells were kept for 4 weeks before a culture was considered negative. MDCK and $\mathrm{NCl}$ cells were incubated for 4 days, harvested by trypsination and stained with the IFA reagents.

\section{Serological studies}

Chlamydial IgM, IgA and IgG antibodies were determined by an enzyme immunoassay with recombinant lipopolysaccharide as antigen (rELISAs medac, Murex Diagnostics SA). The results were then confirmed by a MIF test.

The rELISA test allows the quantitative detection of

Table 2. Viral and bacterial species used in the PCR assay

Respiratory syncytial virus A

Respiratory syncytial virus B

Parainfluenzavirus type 3

Cytomegalovirus

Adenovirus

Rhinovirus

Coxsackievirus B4

Echovirus 11

Chlamydia trachomatis

Mycoplasma pneumoniae

Mycoplasma orale

Mycoplasma salivarium

Mycoplasma hominis

Legionella pneumophila

Pseudomonas aeruginosa

Bordetella pertussis

Mycobacterium tuberculosis

Mycobacterium avium

Neisseria gonorrhoeae

Listeria monocytogenes

Streptococcus pneumoniae

Haemophilus infuenzae

Bacteroides fragilis

Escherichia coli

Staphylococcus aureus 
genus-specific anti-chlamydia IgG, IgA and IgM antibodies. A chemically defined LPS antigen fragment is used that, theoretically, excludes crossreactivity with other organisms. It is now accepted that LPS-antibodies appear very early in the course of infection $[19,20]$. This rELISA test was performed as recommended by the manufacturer. For each result, an index value was defined according to the manufacturer's instructions as OD sample/OD cut-off value. Serological criteria for acute or recent chlamydia infection were either a four-fold rise in IgG index, or an $\operatorname{IgG}$ index $\geqslant 4$ associated with an $\operatorname{IgA}$ index $\geqslant 2$ (with or without the presence of $\operatorname{IgM}$ ) in a single serum sample. A stable IgA, IgM or IgG index in two sera taken at an interval of 2 weeks was regarded as providing no evidence of acute or recent infection. The presence of an IgG response alone on a single serum sample was considered to be compatible with past infection. An IgA or IgM response, or both, with or without an IgG index $\leqslant 4$ were considered as equivocal results.

The MIF test allows the quantitative detection of $\operatorname{IgG}$, $\operatorname{IgA}$ and $\operatorname{IgM}$ antibodies specific to $C$. pneumoniae [21]. Purified elementary bodies of C. psittaci (6BC), C. pneumoniae (TW183) and C. trachomatis (serotype $\mathrm{D}-\mathrm{K}$ ) are used as antigens. The assay was performed as recommended by the manufacturer (Chlamydia Panel, Eurobio, France). A four-fold or greater rise in MIF antibody titre between paired serum specimens, an $\operatorname{IgG}$ antibody titre $\geqslant 512$, and $\operatorname{IgA}$ titre $\geqslant 32$ or an IgM titre $\geqslant 16$ were considered as evidence of acute or recent infection with $C$. pneumoniae. IgM was detected after treatment with RF-factor (Behring) to exclude false-positive reactions. A single IgG titre $<512$ was compatible with past infection. A single IgA titre $<32$ either alone or associated with an IgG titre $<512$ was regarded as an equivocal result.

For both tests, serum samples without IgG, IgA or IgM were defined as negative.

Detection of $M$. pneumoniae-specific antibodies was performed with a commercial ELISA test (Platelia $M$. pneumoniae IgG and IgM immunocapture) according to the manufacturer's instructions. Evidence of infection was defined by one of the following results: a single positive serum IgM titre, seroconversion, a significant increase in IgG titre or an $\operatorname{IgG}$ titre $>40$ arbitrary units $/ \mathrm{ml}$.

\section{Results}

\section{Patients with proven $C$. pneumoniae infection}

Eight $(11.8 \%)$ of the 68 patients tested showed evidence of acute or recent infection with $C$. pneumoniae in one or more tests (PCR, rELISA and MIF test). The results are summarised in Table 3. Six patients were male and two were female. The $C$. pneumoniae infection rate in each group was $5(18.5 \%)$ of 27 for patients with community-acquired pneumonia, $2(9 \%)$ of 22 for the asthmatic patients and $1(5 \%)$ of 19 for patients with an exacerbation of COPD. The rELISA and PCR tests had equal sensitivity. Among the eight proven $C$. pneumoniae-infected patients, four were rELISA positive (cases 1, 2, 3 and 4) and four were PCR positive (cases 4, 5, 6 and 7). Only one patient (case 4) had concordant results with both rELISA and PCR-EIA; two other patients (cases 5 and 6) had concordant results with the MIF test and PCREIA. The last patient (case 8) was PCR-EIA negative, rELISA negative but MIF test positive.

Among the four patients with a positive rELISA test, one seroconverted (case 1) and another (case 4) was PCR-EIA positive; these four patients were all MIF positive with anti-C. pneumoniae IgA titres $\geqslant 32$ and IgG titres of 128-256. Of the four PCR-EIA positive patients, one was both rELISA and MIF positive (case 4), two were MIF positive but rELISA negative (cases 5 and 6), and one had negative serology on the single serum sample examined (case 7). There was no evidence of infection with $M$. pneumoniae or respiratory viruses in the eight patients with $C$. pneumoniae infection.

Table 3. Results of serological tests and PCR-EIA in clinical specimens from eight patients with C. pneumoniae infection

\begin{tabular}{|c|c|c|c|c|c|c|c|c|c|c|}
\hline \multirow[b]{2}{*}{ Case no. } & \multirow[b]{2}{*}{ Diagnosis } & \multirow[b]{2}{*}{ Age/Sex } & \multirow[b]{2}{*}{ Serum } & \multicolumn{3}{|c|}{ rELISA antibody index* } & \multicolumn{3}{|c|}{ MIF antibody titre } & \multirow[b]{2}{*}{ PCR-EIA } \\
\hline & & & & IgG & $\operatorname{IgA}$ & $\operatorname{IgM}$ & IgG & IgA & $\operatorname{IgM}$ & \\
\hline \multirow[t]{2}{*}{1} & \multirow[t]{2}{*}{ Pneumonia } & \multirow[t]{2}{*}{$72 / \mathrm{M}$} & Acute & $\ldots$ & 1.3 & $\ldots$ & 16 & $\ldots$ & $\ldots$ & \multirow[t]{2}{*}{-} \\
\hline & & & Convalescent & 7 & 6.7 & $\ldots$ & 256 & 64 & $\ldots$ & \\
\hline 2 & Asthma & $79 / F$ & Acute & 4.2 & 3 & $\ldots$ & 128 & 32 & $\ldots$ & - \\
\hline \multirow[t]{2}{*}{3} & \multirow[t]{2}{*}{ Asthma } & \multirow[t]{2}{*}{$82 / \mathrm{F}$} & Acute & 5.6 & 4 & $\ldots$ & 256 & 32 & $\ldots$ & \multirow[t]{2}{*}{-} \\
\hline & & & Convalescent & 5.3 & 4.7 & $\ldots$ & ND & ND & ND & \\
\hline \multirow[t]{2}{*}{4} & \multirow[t]{2}{*}{ Pneumonia } & \multirow[t]{2}{*}{$66 / \mathrm{M}$} & Acute & 4.1 & 3.5 & $\ldots$ & 128 & 64 & $\ldots$ & \multirow[t]{2}{*}{+} \\
\hline & & & Convalescent & 4.2 & 3.8 & $\ldots$ & ND & ND & ND & \\
\hline 5 & Pneumonia & $90 / \mathrm{M}$ & Acute & 2.4 & 2.5 & $\ldots$ & ND & 32 & $\ldots$ & + \\
\hline 6 & Pneumonia & $78 / \mathrm{M}$ & Acute & 2.9 & 4 & $\ldots$ & 64 & $\geqslant 128$ & $\ldots$ & + \\
\hline 7 & Pneumonia & $80 / \mathrm{M}$ & Acute & $\ldots$ & $\ldots$ & $\ldots$ & $\ldots$ & $\ldots$ & $\ldots$ & + \\
\hline 8 & COPD & $69 / \mathrm{M}$ & Acute & 2.9 & 2.5 & $\ldots$ & 128 & $\geqslant 64$ & $\ldots$ & - \\
\hline
\end{tabular}

$\mathrm{ND}$, not determined; ..., not detected; COPD, chronic obstructive pulmonary disease.

${ }^{*}$ Expressed as the index of positivity (OD sample/OD cut-off). 


\section{Serological tests for C. pneumoniae}

Acute phase serum specimens from 67 patients were available for serological tests. A second serum sample was available from only $26(38 \%)$ patients and the IgG index was stable in 25 of these patients while one patient seroconverted. With the rELISA test, 37 acute samples were negative for antibody to C. pneumoniae, 12 contained pre-existing IgG to $C$. pneumoniae compatible with past infection, six had IgG and IgA indices compatible with acute or recent infection and 12 had equivocal antibody indices in a single serum sample. Among the six patients with evidence of infection with $C$. pneumoniae, the diagnosis was confirmed by the MIF test in four patients. Of the 12 patients with equivocal rELISA results, the MIF test confirmed two past infections and three acute or recent infections; the seven other MIF tests were negative. In addition, two of the three patients with an equivocal rELISA test and a positive MIF test were PCR-EIA positive (Table 4). Specific IgM antibodies were detected in none of the patients, suggesting that the majority of these cases represented secondary infections. Therefore, seven patients were considered to have serological evidence of current or recent $C$. pneumoniae infection.

\section{PCR-EIA}

C. pneumoniae was identified by PCR-EIA in NPA specimens from four patients. All results were confirmed in a second run of PCR-EIA. One patient who was PCR-EIA positive had high indices of IgG and IgA with rELISA, two patients had an rELISA IgG index $<4$ but an IgA index $>2$ and a positive MIF test; one patient had negative serology by both tests.

\section{Other pathogens}

For seven $(10 \%)$ of the 68 patients, direct isolation or antibody response, or both, suggested current or recent infection with one of the other pathogens investigated: one (1.5\%) patient was infected by M. pneumoniae and six $(8.8 \%)$ by viruses (two influenza virus $\mathrm{B}$, one respiratory syncytial virus sub-group $\mathrm{A}$, three coronavirus) (Table 1).

\section{Discussion}

This study showed that acute respiratory infections in adults were associated with viruses or intracellular bacteria, or both, in $22 \%$ of patients. C. pneumoniae was involved in eight cases (11.8\%), viruses in six cases $(8.8 \%)$ and $M$. pneumoniae in a single case $(1.5 \%)$. Infection with Legionella pneumophila was not investigated. The infection rate for $C$. pneumoniae differed, depending on the group of patients. $C$. pneumoniae was identified in $18.5 \%$ of the patients with community-acquired pneumonia, $9 \%$ of the asthmatic patients and $5 \%$ of the patients with acute exacerbations of COPD. These results are similar to those found in previous studies $[5,11,13,22-26]$. However, poor correlation was found between PCREIA and rELISA serology. Indeed, three of the eight patients with proven $C$. pneumoniae infection were positive only by rELISA and three others were positive only by PCR-EIA (Table 3 ). Concordant positive results were found in only one patient (case 4).

Several factors could explain the disparity between the negative PCR-EIA and the two positive serological tests which were found in three patients (cases 1, 2 and 3). Firstly, except for the seroconversion (case 1), the possibility that the interpretation of the serological results is incorrect cannot be excluded. Indeed, the non-differentiation of species and the arbitrary criteria proposed for positivity in the rELISA test (IgG and $\operatorname{IgA}$ index) may have overestimated the incidence of C. pneumoniae infection. It is generally accepted that IgG antibodies reflect past infection of exposure to $C$. pneumoniae, while IgA levels may reflect persistent or chronic C. pneumoniae infection [7, 8, 27]. However, some authors have reported a high seroprevalence of IgG and IgA antibodies to C. pneumoniae, sometimes with elevated titres $[27,28]$. Secondly, false-positive serology due to non-specific polyclonal stimulation of chlamydial antibodies by other aetiological agents could also have occurred; of other possible agents, only serum antibodies to $M$. pneumoniae were assayed and were negative. Thirdly, false-negative PCR could also have occurred. Several factors may contribute to difficulties in the diagnosis of $C$. pneumoniae infection by PCR: the choice of specimen (throat, NPA, BAL), the quality of collected specimens, their transport to the laboratory, the delay from the time of onset of symptoms to the enrolment in the study, the low numbers of the organism present and the presence of inhibitors of the TaqDNA polymerase in the clinical samples. DNA purification steps and internal controls can overcome the latter problem. The sensitivity of PCR can also be improved by PCR

Table 4. Comparison of PCR-EIA, rELISA and MIF serological tests for the diagnosis of acute or recent $C$. pneumoniae infection

\begin{tabular}{|c|c|c|c|c|c|c|c|c|}
\hline \multirow[b]{2}{*}{ PCR-EIA result } & \multicolumn{4}{|c|}{ rELISA serological test } & \multicolumn{4}{|c|}{ MIF serological test } \\
\hline & ARI & Past infection & Equivocal & Negative & ARI & Past infection & Equivocal & Negative \\
\hline Positive & 1 & 0 & 2 & 1 & 3 & 0 & 0 & 1 \\
\hline Negative & 5 & 12 & 10 & 36 & 4 & 14 & 0 & 45 \\
\hline Total & 6 & 12 & 12 & 37 & 7 & 14 & 0 & 46 \\
\hline
\end{tabular}

ARI, acute or recent infection. 
with nested primers [16, 29], but the risk of contamination is increased. The present study did not use an internal standard or $\beta$-globin control to detect PCR inhibitors, but DNA purification circumvented the inhibition. Optimisation of sampling, specimen handling and PCR techniques are required to improve the efficiency of direct detection of $C$. pneumoniae in the upper respiratory tract.

The reverse pattern of discordant results with a positive PCR-EIA but negative rELISA test was found in three patients (cases 5, 6 and 7). However, as no convalescent phase serum was available for these patients, the rELISA results were incomplete. It has been reported that the rELISA test is a sensitive and specific method for the diagnosis of chlamydial infection, allowing both an early diagnosis and detection of reactivation in older patients [30, 31]. The present study shows that the MIF test increases the sensitivity of diagnosis on a single serum (case 5, 6 and 8$)$.

As a convalescent serum was missing for case 7, which was PCR-EIA positive but serology negative, asymptomatic nasopharyngeal carriage of C. pneumoniae at the time of an acute respiratory illness caused by another agent cannot be excluded [32, 33], but a second serum may have shown a significant increase in IgG titre. Several studies have demonstrated that some patients with positive cell culture or PCR results may not have a detectable antibody response in acute phase sera $[4,14,16]$. Thus the diagnostic value of serological tests on a single acute phase serum specimen is very limited. In primary infection, the diagnosis is missed because of the late onset of antibody production. In adult re-infection, which is a frequent phenomenon, the diagnosis is missed because of the common absence of detectable IgM. In addition, the possible persistence of $\operatorname{IgG}$ and $\operatorname{IgA}$ antibodies at elevated titres does not permit distinction between past and evolving infection [27, 28, 31, 34] and serological criteria for acute or recent infection are difficult to define. It can be argued that a second method of direct detection should have been performed in the present study. A 'gold standard' for the diagnosis of acute $C$. pneumoniae infection has not been established, but in most studies culture or direct fluorescent-antibody (DFA) staining, or both, have been chosen as the preferred method. Cell culture was not used to validate the PCR test in the present study, but it has been demonstrated that PCR is more sensitive than isolation $[15,16,34,35]$.

In conclusion, the present results highlight the difficulty in the diagnosis of $C$. pneumoniae infection. It is clear that a single serological test, a common clinical practice, can lead to misinterpretation. PCREIA is a promising technique for the early detection of $C$. pneumoniae in clinical specimens. The present findings show that the PCR-EIA test was both sensitive and specific. Oligonucleotide hybridisation provides confirmation of the specificity of the amplified product, but it also increases the sensitivity of the PCR assay by a factor of 10 over that achieved by detection on an agarose gel (data not shown). PCR should be considered as a diagnostic alternative to serology, but must be optimised for routine application. Further assessment of different detection methods, including PCR and serological investigation, with better definition of the serological criteria and improved performance of the PCR technique, are necessary to confirm the aetiological role of $C$. pneumoniae in acute and chronic respiratory infections.

We acknowledge Rémi Griffais and Monique Thibon (Laboratory of Chlamydia, Institut Pasteur, Pasteur) for providing primers for $C$. pneumoniae PCR.

\section{References}

1. Grayston JT, Aldous MB, Easton A et al. Evidence that Chlamydia pneumoniae causes pneumonia and bronchitis. $J$ Infect Dis 1993; 168: 1231-1235.

2. Grayston JT, Campbell LA, Kuo C-C et al. A new respiratory tract pathogen: Chlamydia pneumoniae, strain TWAR. $J$ Infect Dis 1990; 161: 618-625.

3. Grayston JT. Infections caused by Chlamydia pneumoniae strain TWAR. Clin Infect Dis 1992; 15: 757-763.

4. Chirgwin K, Roblin PM, Gelling M, Hammerschlag MR, Schachter J. Infection with Chlamydia pneumoniae in Brooklyn. J Infect Dis 1991; 163: 757-761.

5. Blasi F, Cosentini R, Legnani D, Denti F, Allegra L. Incidence of community-acquired pneumonia caused by Chlamydia pneumoniae in Italian patients. Eur $J$ Clin Microbiol Infect Dis 1993; 12: 696-699.

6. Laitinen K, Laurila AL, Leinonen M, Saikku P. Reactivation of Chlamydia pneumoniae infection in mice by cortisone treatment. Infect Immun 1996; 64: 1488-1490.

7. Saikku P, Leinonen M, Tenkanen L et al. Chronic Chlamydia pneumoniae infection as a risk factor for coronary heart disease in the Helsinki Heart Study. Ann Intern Med 1992; 116: 273-278.

8. Mendall MA, Carrington D, Strachan D et al. Chlamydia pneumoniae: risk factors for seropositivity and association with coronary heart disease. J Infect 1995; 30: 121-128.

9. Kuo C-C, Shor A, Campbell LA, Fukushi H, Patton DL, Grayston JT. Demonstration of Chlamydia pneumoniae in atherosclerotic lesions of coronary arteries. J Infect Dis 1993; 167: $841-849$.

10. Muhlestein JB, Hammond EH, Carlquist JF et al. Increased incidence of Chlamydia species within the coronary arteries of patients with symptomatic atherosclerotic versus other forms of cardiovascular disease. J Am Coll Cardiol 1996; 27: $1555-1561$.

11. Hahn DL, Golubjatnikov R. Asthma and Chlamydial Infection: a case series. J Fam Pract 1994; 38: 589-595.

12. Falck G, Heyman L, Gnarpe J, Gnarpe H. Chlamydia pneumoniae and chronic pharyngitis. Scand $J$ Infect Dis 1995; 27: 179-182.

13. Blasi F, Legnani D, Lombardo VM et al. Chlamydia pneumoniae infection in acute exacerbations of COPD. Eur Respir J 1993; 6: 19-22.

14. Gaydos CA, Roblin PM, Hammerschlag MR et al. Diagnostic utility of PCR-enzyme immunoassay, culture, and serology for detection of Chlamydia pneumoniae in symptomatic and asymptomatic patients. J Clin Microbiol 1994; 32: 903-905.

15. Campbell LA, Melgosa MP, Hamilton DJ, Kuo C-C, Grayston JT. Detection of Chlamydia pneumoniae by polymerase chain reaction. J Clin Microbiol 1992; 30: 434-439.

16. Black CM, Fields PI, Messmer TO, Berdal BP. Detection of Chlamydia pneumoniae in clinical specimens by polymerase chain reaction using nested primers. Eur J Clin Microbiol 
Infect Dis 1994; 13: 752-756.

17. Watson MW, al-Mahdawi S, Lamden PR, Clarke IN. The nucleotide sequence of the $60 \mathrm{kDa}$ cysteine rich outer membrane protein of Chlamydia pneumoniae strain IOL-207. Nucleic Acids Res 1990; 18: 5299.

18. Griffais R, Andre PM, Thibon M. K-tuple frequency in the human genome and polymerase chain reaction. Nucleic Acids Res 1991; 19: 3887-3891.

19. Orfila J, Chaigneau C, Sueur JM. Infections respiratoires à Chlamydia pneumoniae. Etude comparative de 7 techniques de diagnostic sérologique. Feuill Biol 1996; 209: 41-47.

20. Saikku P. Diagnosis of acute and chronic Chlamydia pneumoniae infections. Chlamydia infections. Proceedings of the Eighth International Symposium on human chlamydial infections. 1994: 163.

21. Wang SP, Grayston JT. Microimmunofluorescence serological studies with the TWAR organism. In: Oriel JD, Ridgway G, Schachter J, Taylor-Robinson D, Ward M (eds) Chlamydial infections. Cambridge, Cambridge University Press. 1986: $329-332$.

22. Hahn DL, Dodge RW, Golubjatnikov R. Association of Chlamydia pneumoniae (strain TWAR) infection with wheezing, asthmatic bronchitis, and adult-onset asthma. JAMA 1991; 266: $225-230$

23. Allegra L, Blasi F, Centanni $\mathrm{S}$ et al. Acute exacerbations of asthma in adults: role of Chlamydia pneumoniae infection. Eur Respir J 1994; 7: 2165-2168.

24. Grayston JT, Diwan VK, Cooney M, Wang SP. Communityand hospital-acquired pneumonia associated with Chlamydia TWAR infection demonstrated serologically. Arch Intern Med 1989; 149: 169-173

25. Jantos CA, Wienpahl B, Schiefer HG, Wagner F, Hegemann JH. Infection with Chlamydia pneumoniae in infants and children with acute lower respiratory tract disease. Pediatr Infect Dis $J$ 1995; 14: 117-122.

26. Resta O, Monno R, Saracino A, Leone E, Gramiccioni E, Fumarola D. Chlamydia pneumoniae infection in Italian patients. Monaldi Arch Chest Dis 1995; 50: 173-176.

27. Paltiel O, Kark JD, Leinonen M, Saikku P. High prevalence of antibodies to Chlamydia pneumoniae; determinants of IgG and IgA seropositivity among Jerusalem residents. Epidemiol Infect 1995; 114: 465-473.

28. Ducroix JP, Leduc I, Sueur JM et al. Limites de la sérologie dans les infections à Chlamydia pneumoniae. XXXIV e Congrès de la Société Nationale Française de Médecine Interne. Amiens, 20-22 Juin 1996.

29. Khan MA, Potter CW. The nPCR detection of Chlamydia pneumoniae and Chlamydia trachomatis in children hospitalized for bronchiolitis. J Infect 1996; 33: 173-175.

30. Biendo M, Orfila J. Sérodiagnostic de Chlamydia trachomatis et de Chlamydia pneumoniae. Evaluation par comparaison de deux méthodes: micro-immunofluorescence et ELISA. Etude de 216 sérums congolais. [Serodiagnosis of Chlamydia trachomatis and Chlamydia pneumoniae. Evaluation comparing two methods: microimmunofluorescence and ELISA. A study of 216 Congolese sera.] Bull Soc Pathol Exot Filiates 1994; 87: 81-84.

31. Ekman MR, Leinonen $M$, Syrjälä $H$, Linnanmäki E, Kujala $P$, Saikku P. Evaluation of serological methods in the diagnosis of Chlamydia pneumoniae pneumonia during an epidemic in Finland. Eur J Clin Microbiol Infect Dis 1993; 12: 756-760.

32. Hammerschlag MR, Chirgwin K, Roblin PM et al. Persistent infection with Chlamydia pneumoniae following acute respiratory illness. Clin Infect Dis 1992; 14: 178-182.

33. Hyman CL, Roblin PM, Gaydos CA, Quinn TC, Schachter J, Hammerschlag MR. Prevalence of asymptomatic nasopharyngeal carriage of Chlamydia pneumoniae in subjectively healthy adults: assessment by polymerase chain reaction-enzyme immunoassay and culture. Clin Infect Dis 1995; 20: 1174-1178.

34. Thom DH, Grayston JT, Campbell LA, Kuo CC, Diwan VK, Wang SP. Respiratory infections with Chlamydia pneumoniae in middle-aged and older adult outpatients. Eur $J$ Clin Microbiol Infect Dis 1994; 13: 785-792.

35. Dalhoff K, Maass M. Chlamydia pneumoniae pneumonia in hospitalized patients. Clinical characteristics and diagnostic value of Polymerase Chain Reaction detection in BAL. Chest 1996; 110: 351-356. 